\title{
Article
}

\section{Analyses of Swallowing Function and Its Related Factors in Community-Dwelling Elderly Patients: A Case-Control Study}

\author{
Yoichiro Ogino ${ }^{1, *(\mathbb{C}}$, Hiroki Suzuki ${ }^{2,3}$, Yasunori Ayukawa ${ }^{1,2}$, , Akio Jinnouchi ${ }^{3}$ and Kiyoshi Koyano ${ }^{4}$ \\ 1 Section of Fixed Prosthodontics, Division of Oral Rehabilitation, Faculty of Dental Science, Kyushu University, \\ Fukuoka 812-8582, Japan; ayukawa@dent.kyushu-u.ac.jp \\ 2 Section of Implant and Rehabilitative Dentistry, Division of Oral Rehabilitation, Faculty of Dental Science, \\ Kyushu University, Fukuoka 812-8582, Japan; zookey456odpmf@gmail.com \\ 3 Department of Dentistry, Inouekai Medical Corporation Sasaguri Hospital, Sasaguri Town, Kasuya County, \\ Fukuoka 811-2413, Japan; gin741219@icloud.com \\ 4 Division of Advanced Dental Devices and Therapeutics, Faculty of Dental Science, Kyushu University, \\ Fukuoka 812-8582, Japan; koyano@dent.kyushu-u.ac.jp \\ * Correspondence: ogino@dent.kyushu-u.ac.jp; Tel.: +81-92-642-6371
}

Citation: Ogino, Y.; Suzuki, H.; Ayukawa, Y.; Jinnouchi, A.; Koyano, K. Analyses of Swallowing Function and Its Related Factors in Community-Dwelling Elderly Patients: A Case-Control Study. J. Clin. Med. 2021, 10, 3437. https:// doi.org/10.3390/jcm10153437

Academic Editor: Gianrico Spagnuolo

Received: 25 June 2021

Accepted: 1 August 2021

Published: 2 August 2021

Publisher's Note: MDPI stays neutral with regard to jurisdictional claims in published maps and institutional affiliations.

Copyright: (c) 2021 by the authors. Licensee MDPI, Basel, Switzerland. This article is an open access article distributed under the terms and conditions of the Creative Commons Attribution (CC BY) license (https:/ / creativecommons.org/licenses/by/ $4.0 /)$.

\begin{abstract}
This retrospective case-control study evaluated the prevalence of declined swallowing function and the association with oral functions and gender in community-dwelling elderly patients. Their profiles, the results of swallowing function (Eating Assessment Tool: EAT-10) and other oral functions (oral dryness, maximum occlusal force (MOF), tongue-lip motor function (oral diadochokinesis: ODK), maximum tongue pressure (MTP) and masticatory performance (MP)) were extracted for analyses. The patients were categorized into three groups according to EAT-10 score (Group 1: 0, Group 2: 1 and 2, Group 3: $\geq 3)$. In total, 242 patients were enrolled and 46 of them (19.0\%) were categorized into declined swallowing function (Group 3). In two-group comparisons (Group 1, 2 versus Group 3), significant differences were identified in age and the number of remaining teeth, but they were not identified in three-group comparisons. The patients with declined swallowing function (Group 3) had significantly lower function in ODK and MTP. Multiple logistic regression analyses identified that declined swallowing function was independently associated with declined functions in ODK / ka / (OR: 5.31, 95\% CI: 1.03-27.23, $p=0.04$ ) and in MTP (OR: 2.74, 95\% CI: 1.12-6.66, $p=0.03$ ). This study could confirm the critical role of tongue functions in swallowing in community-dwelling elderly patients.
\end{abstract}

Keywords: swallowing function; oral hypofunction; community-dwelling elderly patients; tonguelip motor function; maximum tongue pressure

\section{Introduction}

One of the health issues in the elderly is dysphagia [1,2]. Dysphagia, defined as a feeling that food sticks in throat or chest [3], is caused by aging, the decline in swallowingrelated muscle functions including tongue, xerostomia, physical frailty, sarcopenia and comorbidities [1-7]. Furthermore, dysphagia often leads to malnutrition, aspiration pneumonia, morbidity and mortality [1-8]. Early recognition and diagnosis of this chronic symptom in the elderly is an urgent issue.

The swallowing process consists of three sequential phases; oral, pharyngeal, and esophageal phases [9]. This process requires a coordination of neuromuscular activity. Prior to swallowing, foods must be chewed and be mixed with saliva to form a bolus. The teeth or well-functioning dental prostheses, a sensory-motor activity by masticatory muscles and tongue, and salivary secretion play a crucial role in mastication [10-13]. The bolus is placed on tongue surface and is transferred to the pharynx by the elevation and the contraction of tongue and soft palate (oral phase). This process is a voluntary process. Sequentially, the bolus moves through the oropharynx (pharyngeal phase) and the 
esophagus (esophageal phase) into the stomach, which are involuntary processes [9-11]. Anatomical or physiologic disorders related to these processes result in dysphagia [14]. Especially, the poor oral functions might be directly relevant to oral phase dysphagia. However, oral functions in dysphagia patients have not been evaluated clearly.

The concept of "oral hypofunction" was introduced in 2018 [15]. This position paper proposed diagnostic criteria in seven oral signs or symptoms, which included a decline in swallowing function (dysphagia). Recent studies evaluated the oral functions and the association between oral functions and systemic conditions based on this concept [16-21]. It means that we can recognize that these oral functions are regarded as the typical oral functions.

The aims of this study were to evaluate the prevalence ratio of declined swallowing function in community-dwelling elderly patients and to compare their oral functions between the patients with and without declined swallowing function. The null hypothesis of this study was that there was no significant difference in oral functions between the patients with and without declined swallowing function and no independent factors are identified against swallowing function.

\section{Materials and Methods}

\subsection{Ethical Approval and Study Population}

This retrospective case-control study was approved by the institutional ethics committee (Approval Number \#19). This study was conducted in accordance with the ethical principle of Helsinki Declaration. The community-dwelling elderly patients (65 years or older) who visited our institutional dental clinic for a regular check-up from April 2018 to March 2019 could be the candidates of this study. They had completed their prosthetic treatment and visited for the regular teeth cleaning and/or the maintenance of periodontal tissue and their prostheses. The inclusion criteria were as follows: (1) the patients who had been measured their oral functions described below after the completion of prosthetic treatment, (2) the patients who could use their prostheses without any problems, and (3) the patients where edentulous and/or partially edentulous sites were rehabilitated with fixed partial prostheses and/or removable dental prostheses. The following patients were excluded: (1) the patients who had ongoing dental treatment except for a regular check-up, (2) the patients who had the presence and the history of radiotherapy for head and neck cancer, and (3) the patients who had the presence and the history of the disease caused declined swallowing function such as stroke, head injury, tongue and salivary gland disease, or dementia.

At first, the patient profiles (age, gender, the number of remaining teeth and body mass index (BMI)) were extracted from the medical chart. Next, the enrolled patients were divided into three groups according to the score of Eating Assessment Tool (EAT-10; a self-administered questionnaire for swallowing) [15,16,18,20-22]: (1) EAT-10 score: 0 (Group 1), (2) EAT-10 score: 1 and 2 (Group 2), and (3) EAT-10 score $\geq 3$ (Group 3). The assessment criterion for declined swallowing function (dysphagia) was EAT-10 score $\geq 3$ (Group 3) [15,22].

\subsection{Measurement of Oral Functions}

Oral functions based on the concept of "oral hypofunction" had been measured [15]. Oral functions used for the analyses were as follows.

\subsubsection{Oral Dryness}

Oral dryness was assess using an oral moisture checker (Mucus, Life Co., Ltd., Saitama, Japan) $[15-18,20,21]$. The sensor of this checker was pressed against tongue for a few seconds and the measurement value was presented [15]. The threshold value was 27 [15]. 


\subsubsection{Maximum Occlusal Force (MOF)}

MOF was calculated using pressure indicating film (Dental Prescale II, GC, Tokyo, Japan) $[15-17,19]$. The patients were asked to clench the sheet in intercuspal position for 3 $\mathrm{s}$ and the sheet was analyzed using the software (Bite Force Analyzer, GC, Tokyo, Japan) to calculate MOF. The threshold value was $500 \mathrm{~N}$ [15].

\subsubsection{Tongue-Lip Motor Function (Oral Diadochokinesis: ODK)}

ODK has been used to define tongue-lip motor function [15-18,20,21]. The patients were asked to utter the syllables $/ \mathrm{pa} /, / \mathrm{ta} /$, or $/ \mathrm{ka} /$ as many as possible for $5 \mathrm{~s}$. These sounds were recorded using a measurement device (Kenko-kun; Takei Scientific Instruments Co., Ltd., Niigata, Japan). This device could calculate the number of sounds per second after 5 seconds' recording. In general, $/ \mathrm{pa} /, / \mathrm{ta} /$ and $/ \mathrm{ka} /$ are used to evaluate motor function of lip, anterior region of the tongue and posterior region of the tongue respectively as a previous study showed [15]. The threshold value was 6 times per second [15].

\subsubsection{Maximum Tongue Pressure (MTP)}

MTP was measured using a specific measuring device with a balloon of the probe (JMTPM; JMS Co., Ltd., Hiroshima, Japan) [15-21]. The patients were instructed to compress the balloon on the tongue to anterior palate for $7 \mathrm{~s}$. The device showed MTP and the average value was recorded after 3 measurements. The threshold value was $30 \mathrm{kPa}$ [15].

\subsubsection{Masticatory Performance (MP)}

MP was measured as the previous studies evaluated [15-17,19]. The patients were instructed to chew $2 \mathrm{~g}$ of gummy jelly voluntary for $20 \mathrm{~s}$ without swallowing. The crushed gummy jelly was spit out with saliva and $10 \mathrm{~mL}$ rinsing water. Glucose concentration from crushed gummy jelly was measured using a measuring device (Gluco Sensor GS-II, GC. Tokyo, Japan). The threshold value was $100 \mathrm{mg} / \mathrm{dL}$ [15].

\subsection{Statistical Analyses}

The numeric data including patient profiles (age, number of remaining teeth and BMI) and the measurement values of oral functions were presented as medians with interquartile ranges (IQRs). The comparisons between normal swallowing function groups (Group 1 and 2) and a declined swallowing function group (Group 3) were also evaluated by a Mann-Whitney U test (two-group comparisons). Three-group comparisons among Groups 1,2 , and 3 were performed via using the Steel-Dwass test after Kruskal-Wallis test. In addition, a multiple logistic regression analysis was also performed to examine whether declined swallowing function was independently associated with other oral functions and gender, and age- and the number of remaining teeth-adjusted odds ratios (ORs) with 95\% confidence intervals (95\% CIs) were also calculated. For all statistical analyses, JMP Pro 16 (SAS Institute Inc., Cary, NC, USA) was used and $p$-values less than 0.05 were considered statistically significant.

\section{Results}

\subsection{Patient Profiles}

Patient profiles were described in Table 1 . In total, the enrolled patients were 242 community-dwelling elderly people (male and female: 89 and 153). The patients who were rehabilitated with removable dental prostheses (removable partial dentures and/or complete dentures) were 190 patients and 52 patients were natural teeth dental arches or were rehabilitated with fixed partial dentures (no removable dental prostheses). No patients were rehabilitated with implant prostheses. Oral functions in the patients with removable dental prostheses were measured with their dentures. The results of EAT-10 demonstrated that 46 patients (19.0\%, male and female: $23(25.8 \%)$ and $23(15.0 \%))$ were defined as the patients with declined swallowing function. The statistical analyses in 
two-group comparisons revealed the significant differences in age ( $p<0.05$, Mann-Whitney $\mathrm{U}$ test) and the number of remaining teeth ( $p<0.05$, Mann-Whitney $\mathrm{U}$ test) between Group 1 and 2 versus Group 3, although no significant difference in BMI was identified. However, multiple statistical analyses identified no significant differences among three groups in these three categories ( $p>0.05$, Steel-Dwass test after Kruskal-Wallis test).

Table 1. Profiles of enrolled patients.

\begin{tabular}{cccccc}
\hline & All Patients & $\begin{array}{c}\text { Groups 1 and 2 } \\
\text { (EAT-10: 0-2) }\end{array}$ & $\begin{array}{c}\text { Group 1 } \\
\text { (EAT-10: 0) }\end{array}$ & $\begin{array}{c}\text { Group 2 } \\
\text { (EAT-10: 1, 2) }\end{array}$ & $\begin{array}{c}\text { Group 3 } \\
\text { (EAT-10 } \geq 3)\end{array}$ \\
\hline $\begin{array}{c}\text { Gender } \\
\text { (male:female) }\end{array}$ & $89: 153$ & $66: 130$ & $48: 90$ & $18: 40$ & $23: 23$ \\
\hline Age & $78(71-84)$ & $77^{*}(71-83)$ & $77(71-82)$ & $78(74-84)$ & $82(71-87)$ \\
\hline $\begin{array}{c}\text { Number of } \\
\text { remaining teeth }\end{array}$ & 18 & $19 *$ & 18 & 20 & $(11.5$ \\
\hline BMI & $(7-24)$ & $(8-25)$ & $(7-25)$ & $(9-26)$ & 22.5 \\
$(19.9-24.6)$ & $(20.3-24.9)$ & $(20.4-24.6)$ & $(19.5-25.2)$ & $(18.4-24.25)$ \\
\hline
\end{tabular}

EAT-10: Eating Assessment Tool-10. The values were described as median and interquartile range. ${ }^{*} p<0.05$, vs. Group 3, Mann-Whitney $\mathrm{U}$ test (two-group comparison). No significant differences among Groups 1, 2 and 3, Steel-Dwass test after Kruskal-Wallis test (three-group comparison).

\subsection{Comparisons of Oral Functions}

Oral functions were also compared between Groups 1 and 2 versus Group 3 (twogroup comparisons, normal swallowing function groups and a declined swallowing function group), and among three groups (three-group comparisons) (Table 2). In two-group comparisons, the patients who belonged to Group 3 showed the significant lower values in all ODKs and MTP compared to Group 1 and 2 patients $(p<0.01$, except for ODK $/ \mathrm{pa} /$ sound $(p<0.05)$, Mann-Whitney U test). Furthermore, three-group comparisons demonstrated that there were significant differences in ODK each sound between Group 1 and Group 3 (/pa/ and /ta /; $p<0.05$, / ka/; $p<0.01$, Steel-Dwass test after the KruskalWallis test), and in MTP between Group 1 and Group $3(p<0.01$, Steel-Dwass test after Kruskal-Wallis test), and between Group 1and Group $2(p<0.05$, Steel-Dwass test after Kruskal-Wallis test).

Table 2. Measurement values (medians and interquartile ranges) of oral functions in each group.

\begin{tabular}{cccccc}
\hline & All Patients & $\begin{array}{c}\text { Groups 1 and 2 } \\
\text { (EAT-10: 0-2) }\end{array}$ & $\begin{array}{c}\text { Group 1 } \\
\text { (EAT-10: 0) }\end{array}$ & $\begin{array}{c}\text { Group 2 } \\
\text { (EAT-10: 1, 2) }\end{array}$ & $\begin{array}{c}\text { Group 3 } \\
\text { (EAT-10 } \geq \text { 3) }\end{array}$ \\
\hline $\begin{array}{c}\text { Oral } \\
\text { dryness }\end{array}$ & $\begin{array}{c}27.1 \\
(24.6-29.4)\end{array}$ & $\begin{array}{c}27.0 \\
(24.4-29.4)\end{array}$ & $\begin{array}{c}27.0 \\
(24.4-29.5)\end{array}$ & $\begin{array}{c}26.9 \\
(24.5-29.0)\end{array}$ & $\begin{array}{c}27.2 \\
(26.0-29.6)\end{array}$ \\
\hline MOF & 406.7 & 422.2 & 419.0 & 470.3 & 328.2 \\
& $(229.4-663.6)$ & $(237.1-683.2)$ & $(229.3-659.6)$ & $(254.5-711.1)$ & $(215.6-581.4)$ \\
\hline ODK & 5.6 & $5.8^{*}$ & 5.8 & 5.6 & $4.9^{\#}$ \\
/pa/ & $(4.4-6.2)$ & $(4.8-6.2)$ & $(4.8-6.2)$ & $(4.5-6.1)$ & $(3.8-6.1)$ \\
\hline ODK & 5.4 & $5.4^{* *}$ & 5.5 & 5.3 & $5.0^{\#}$ \\
/ta/ & $(4.6-6.2)$ & $(4.6-6.2)$ & $(4.8-6.2)$ & $(4.3-6.2)$ & $(4.1-5.8)$ \\
\hline ODK & 5.0 & $5.2^{* *}$ & 5.2 & 5.0 & $4.5^{\# \#}$ \\
/ka/ & $(4.0-5.8)$ & $(4.2-5.8)$ & $(4.4-5.8)$ & $(4.1-5.9)$ & $(3.4-5.5)$ \\
\hline MTP & 25.7 & $27.3^{* *}$ & 28.0 & $24.3^{\$}$ & $22.3^{\# \#}$ \\
\hline MP & $(20.0-31.3)$ & $(20.8-32.5)$ & $(21.6-34.0)$ & $(17.1-29.3)$ & $(16.0-26.9)$ \\
\hline
\end{tabular}

MOF: maximum occlusal force, ODK: oral diadochokinesis for tongue-lip motor function, MTP: maximum tongue pressure, MP: masticatory performance. ${ }^{*} p<0.05$ and ${ }^{* *} p<0.05$, vs. Group 3, Mann-Whitney U test (two-group comparison). ${ }^{\#} p<0.05,{ }^{\# \#} p<0.01$ and ${ }^{\$} p<0.05$, vs. Group 1 Steel-Dwass test after Kruskal-Wallis test (three-group comparison). 


\subsection{Odds Ratios (ORs) and a Multiple Logistic Regression Analysis}

The results of multiple logistic regression analyses including calculations of ORs were shown in Table 3. The model summary revealed that this model was statistically significant $(p<0.01)$. This analysis identified that declined swallowing function (EAT-10 score $\geq 3$ ) was independently associated with declined functions in ODK / ka/ (OR: 5.31, 95\% CI: 1.03-27.23, $p=0.04$ ) and in MTP (OR: 2.74, 95\% CI: 1.12-6.66, $p=0.03$ ).

Table 3. Odds ratios and multiple logistic regression analysis.

\begin{tabular}{cccc}
\hline & Odds Ratio & $\begin{array}{c}\mathbf{9 5 \%} \\
\text { Confidence Interval }\end{array}$ & $\begin{array}{c}p \text {-Value } \\
\text { (Multiple Logistic Regression Analysis) }\end{array}$ \\
\hline Oral & 0.71 & $0.36-1.41$ & 0.33 \\
dryness & 1.88 & $0.83-4.28$ & 0.13 \\
MOF & 0.99 & $0.37-2.65$ & 0.98 \\
ODK /pa/ & 0.83 & $0.28-2.47$ & 0.74 \\
ODK /ta/ & 5.31 & $1.03-27.23$ & 0.04 \\
ODK / ka/ & 2.74 & $0.12-6.66$ & 0.03 \\
MTP & 0.61 & $0.29-1.32$ & 0.21 \\
MP & 0.54 & 0.08 & 0.08 \\
Gender & &
\end{tabular}

MOF: maximum occlusal force, ODK: oral diadochokinesis for tongue-lip motor function, MTP: maximum tongue pressure, MP: masticatory performance.

\section{Discussion}

As the previous studies reported, declined swallowing function (dysphagia) has been known as a multifactorial disorder [1-7]. A recent study based on a self-report questionnaire with a frailty checklist presented that dysphagia was independently associated with oral, physical, cognitive and psychological frailty in community-dwelling elderly people [23]. Swallowing is a complex behavior including the reflexive and voluntary actions, and can be assumed as a result of the coordination of several functions including perioral muscles, tongue and neural network $[9,10]$. Hence, this study was conducted as a retrospective casecontrol study to compare the measurement values of oral functions between communitydwelling elderly patients with and without declined swallowing function. However, this study also aimed to identify the factors independently associated with declined swallowing function.

Since the concept of "oral hypofunction" has been introduced, typical oral functions become evident. The oral functions evaluated in this study were selected based on this concept. The present study clearly showed that the significant differences in tongue-lip motor function (ODK) and MTP were observed between the elderly patients with and without declined swallowing function, and above all it is suggested that motor function of posterior region of tongue (ODK / ka/) and MTP play a crucial role in swallowing function. These findings clearly showed the importance of tongue functions in swallowing. The previous studies indicated a crucial role of tongue pressure or MTP in swallowing [24-27]. The key role of tongue-lip motor function in swallowing was suggested in several studies $[28,29]$ and the studies also showed the prevalence of the elderly people who showed declined swallowing function and lower ODK [30-32]. Regarding tongue-lip motor function (ODK), clear evidence for the association of ODK with swallowing function is still insufficient, because there have been few studies that evaluated swallowing function using three of tongue-lip motor functions proposed by Minakuchi et al. On this point, this study demonstrated the significance of motor function of posterior region of tongue (ODK $/ \mathrm{ka} /$ ) as a result of three kinds of ODK evaluations. Interestingly, MTP in this study was measured by the elevation of the tongue. This motion works for the transfer of bolus to the back of the mouth and is followed by the protrusion of the tongue to squeeze the bolus back along the palate and into the pharynx $[9,10]$. The former motion is similar to / ta/ pronunciation and the latter is similar to $/ \mathrm{ka} /$ pronunciation. This study confirmed the significance of these motions, and the motor function of posterior region of tongue or the protrusion 
of the tongue measured by ODH / ka/, in particular, can be one of the crucial factors in swallowing function. We believe that these findings can recommend MTP and ODK evaluation for the patients with declined swallowing function as screening factors, and the rehabilitation of both functions might contribute to its improvement. As the previous studies showed, the tongue strengthening exercise is helpful in improving swallowing function [33-36], although further well-designed studies will be required.

In this study, there were no differences in the other oral functions between the patients with and without declined swallowing function. However, the previous studies suggested the association of each oral functions with swallowing. Although oral dryness or xerostomia could be a risk factor of declined swallowing function, the previous studies suggested that it depended on the severity of oral dryness [37,38]. The subjects in this study were relatively better condition as presented in Table 2, resulting that we could not identify oral dryness as a significant factor. Regarding MOF and MP, it is important to note that the previous studies showed the significant correlation between these two factors [12,39-42]. In addition, several studies showed the correlation between MP and MTP [12,13,42,43], and between MOF and MTP [44]. Although this study suggested more critical role of MTP in swallowing function compared to these factors, we need to recognize the correlations between these factors and swallowing function. This means that relative effects of them on swallowing function should be noted for the rehabilitation

Although we believed that this study has revealed novel and critical findings, we need to describe the limitation of this study, which is the characteristics of the subjects in this study. The subjects of this study were community-dwelling elderly patients who visited for a regular check-up after the completion of the dental treatment. As described in inclusion and exclusion criteria, all of the subjects might be defined as healthy elderly population. However, we did not follow the detailed systemic conditions such as the history of systemic diseases and medications, which could be confounding factors. In addition, it is not clear the ratios of elderly people who can visit dental clinics. This means that the definition of "community-dwelling elderly patients" is not same as "communitydwelling elderly people". According to this limitation, we decided that the title of this study included "community-dwelling elderly patients", not "community-dwelling elderly people". In addition, the subjects were limited to the patients due to the retrospective study and the sample size was not enough. However, we tried to calculate the sample size based on the previous studies [21,23,45], and the prevalence of these factors were wide varieties and it was difficult to calculate the sample size. The data analyses regarding the differences between genders and specific findings in each gender were not conducted due to the limitation of sample size. However, multiple logistic regression analysis revealed that $p$-value in gender was 0.08 and suggested the effect of gender on swallowing. We hope to have further studies that include a wider range of population, although we believe the result of this study was beneficial to understand the etiology of declined swallowing function.

\section{Conclusions}

Within the limitation of this study, the present analyses suggested $19.0 \%$ of the subjects (male: $25.8 \%$ and female: $15.0 \%$ ) showed the declined swallowing function. Analyses of oral functions revealed that MTP and tongue-lip motor function in the patients without the declined swallowing function were significantly better than the patients with the declined swallowing function. Multiple logistic regression analysis revealed that the motor function of posterior region of tongue (ODK $/ \mathrm{ka} /$ ) and MTP were significant independent factors in swallowing function. However, the subjects of this study were limited to the patients who could visit dental clinics for a regular check-up and more subjects who have various backgrounds must be enrolled to evaluate the real swallowing etiology in communitydwelling elderly people.

Author Contributions: Conceptualization, Y.O. and H.S.; methodology, Y.O.; software, Y.O. and H.S.; validation, Y.O., H.S. and Y.A.; formal analysis, Y.O.; investigation, H.S. and A.J.; resources, H.S. and 
A.J.; data curation, Y.O.; writing—original draft preparation, Y.O.; writing—review and editing, K.K.; visualization, Y.O.; supervision, Y.A. and K.K.; project administration, H.S.; funding acquisition, H.S. and A.J. All authors have read and agreed to the published version of the manuscript.

Funding: This research received no external funding.

Institutional Review Board Statement: The study was conducted according to the guidelines of the Declaration of Helsinki, and approved by the Institutional Review Board of Sasaguri Hospital (Protocol Code \#19).

Informed Consent Statement: Patient consent was waived due to a retrospective study which used extracted data from medical record.

Data Availability Statement: The datasets used and/or analyzed during the current study are available from the corresponding author upon reasonable request.

Conflicts of Interest: One of the authors (K.K.) belongs to the Division of Advanced Dental Devices and Therapeutics, Faculty of Dental Science, Kyushu University. This division is endowed by GC Corporation, Tokyo, Japan. GC Corporation had no specific roles in this study. The other authors declare no conflicts of interest.

\section{References}

1. Sura, L.; Madhavan, A.; Carnaby, G.; Crary, M.A. Dysphagia in the elderly: Management and nutritional considerations. Clin. Interv. Aging 2012, 7, 287-298. [CrossRef]

2. Madhavan, A.; LaGorio, L.A.; Crary, M.A.; Dahl, W.J.; Carnaby, G.D. Prevalence of and Risk Factors for Dysphagia in the Community Dwelling Elderly: A Systematic Review. J. Nutr. Health Aging 2016, 20, 806-815. [CrossRef]

3. Eslick, G.D.; Talley, N.J. Dysphagia: Epidemiology, risk factors and impact on quality of life-A population-based study. Aliment. Pharmacol. Ther. 2008, 27, 971-979. [CrossRef]

4. Maeda, K.; Akagi, J. Decreased tongue pressure is associated with sarcopenia and sarcopenic dysphagia in the elderly. Dysphagia 2015, 30, 80-87. [CrossRef] [PubMed]

5. Ohara, Y.; Yoshida, N.; Kono, Y.; Hirano, H.; Yoshida, H.; Mataki, S.; Sugimoto, K. Effectiveness of an oral health educational program on community-dwelling older people with xerostomia. Geriatr. Gerontol. Int. 2015, 15, 481-489. [CrossRef]

6. Baijens, L.W.; Clavé, P.; Cras, P.; Ekberg, O.; Forster, A.; Kolb, G.F.; Leners, J.C.; Masiero, S.; Mateos-Nozal, J.; Ortega, O.; et al. European Society for Swallowing Disorders-European Union Geriatric Medicine Society white paper: Oropharyngeal dysphagia as a geriatric syndrome. Clin. Interv. Aging 2016, 11, 1403-1428. [CrossRef] [PubMed]

7. Rech, R.S.; Baumgarten, A.; Colvara, B.C.; Brochier, C.W.; de Goulart, B.; Hugo, F.N.; Hilgert, J.B. Association between oropharyngeal dysphagia, oral functionality, and oral sensorimotor alteration. Oral Dis. 2018, 24, 664-672. [CrossRef] [PubMed]

8. Hägglund, P.; Koistinen, S.; Olai, L.; Ståhlnacke, K.; Wester, P.; Levring Jäghagen, E. Older people with swallowing dysfunction and poor oral health are at greater risk of early death. Community Dent. Oral Epidemiol. 2019, 47, 494-501. [CrossRef]

9. Jean, A. Brain stem control of swallowing: Neuronal network and cellular mechanisms. Physiol. Rev. 2001, 81, 929-969. [CrossRef]

10. Matsuo, K.; Palmer, J.B. Anatomy and physiology of feeding and swallowing: Normal and abnormal. Phys. Med. Rehabil. Clin. N. Am. 2008, 19, 691-707. [CrossRef]

11. Peyron, M.A.; Woda, A.; Bourdiol, P.; Hennequin, M. Age-related changes in mastication. J. Oral Rehabil. 2017, 44, 299-312. [CrossRef]

12. Kugimiya, Y.; Watanabe, Y.; Igarashi, K.; Hoshino, D.; Motokawa, K.; Edahiro, A.; Ueda, T.; Takano, T.; Sakurai, K.; Taniguchi, Y.; et al. Factors associated with masticatory performance in community-dwelling older adults: A cross-sectional study. J. Am. Dent. Assoc. 2020, 151, 118-126. [CrossRef] [PubMed]

13. Maruyama, M.; Morita, K.; Kimura, H.; Nishio, F.; Yoshida, M.; Tsuga, K. Association between masticatory ability and oral functions. J. Clin. Exp. Dent. 2020, 2, e1011-e1014. [CrossRef] [PubMed]

14. Sasegbon, A.; Hamdy, S. The anatomy and physiology of normal and abnormal swallowing in oropharyngeal dysphagia. Neurogastroenterol. Motil. 2017, 29. [CrossRef] [PubMed]

15. Minakuchi, S.; Tsuga, K.; Ikebe, K.; Ueda, T.; Tamura, F.; Nagao, K.; Furuya, J.; Matsuo, K.; Yamamoto, K.; Kanazawa, M.; et al. Oral hypofunction in the older population: Position paper of the Japanese Society of Gerodontology in 2016. Gerodontology 2018, 35, 317-324. [CrossRef]

16. Matsuo, K.; Kito, N.; Ogawa, K.; Izumi, A.; Masuda, Y. Effects of textured foods on masticatory muscle activity in older adults with oral hypofunction. J. Oral Rehabil. 2020, 47, 180-186. [CrossRef]

17. Iyota, K.; Mizutani, S.; Oku, S.; Asao, M.; Futatsuki, T.; Inoue, R.; Ima, Y.; Kashiwazaki, H. A Cross-Sectional Study of Age-Related Changes in Oral Function in Healthy Japanese Individuals. Int. J. Environ. Res. Public Health 2020, 17, 1376. [CrossRef] [PubMed]

18. Kugimiya, Y.; Watanabe, Y.; Ueda, T.; Motokawa, K.; Shirobe, M.; Igarashi, K.; Hoshino, D.; Takano, T.; Sakurai, K.; Taniguchi, Y.; et al. Rate of oral frailty and oral hypofunction in rural community-dwelling older Japanese individuals. Gerodontology 2020, 37, 342-352. [CrossRef] 
19. Fujikawa, N.; Ogino, Y.; Koga, S.; Ueno, M.; Moroi, R.; Koyano, K. Validation of masticatory function and related factors in maxillectomy patients based on the concept of "oral hypofunction": A retrospective cross-sectional study. J. Prosthodont. Res. 2020, in press. [CrossRef]

20. Ogino, Y.; Fujikawa, N.; Koga, S.; Moroi, R.; Koyano, K. A retrospective cross-sectional analysis of swallowing and tongue functions in maxillectomy patients. Support. Care Cancer 2021, in press. [CrossRef]

21. Nakamura, M.; Hamada, T.; Tanaka, A.; Nishi, K.; Kume, K.; Goto, Y.; Beppu, M.; Hijioka, H.; Higashi, Y.; Tabata, H.; et al. Association of Oral Hypofunction with Frailty, Sarcopenia, and Mild Cognitive Impairment: A Cross-Sectional Study of Community-Dwelling Japanese Older Adults. J. Clin. Med. 2021, 10, 1626. [CrossRef] [PubMed]

22. Belafsky, P.C.; Mouadeb, D.A.; Rees, C.J.; Pryor, J.C.; Postma, G.N.; Allen, J.; Leonard, R.J. Validity and reliability of the Eating Assessment Tool (EAT-10). Ann. Otol. Rhinol. Laryngol. 2008, 117, 919-924. [CrossRef] [PubMed]

23. Nishida, T.; Yamabe, K.; Honda, S. Dysphagia is associated with oral, physical, cognitive and psychological frailty in Japanese community-dwelling elderly persons. Gerodontology 2020, 37, 185-190. [CrossRef]

24. Ono, T.; Hori, K.; Nokubi, T. Pattern of tongue pressure on hard palate during swallowing. Dysphagia 2004, 19, 259-264. [CrossRef]

25. Yoshida, M.; Kikutani, T.; Tsuga, K.; Utanohara, Y.; Hayashi, R.; Akagawa, Y. Decreased tongue pressure reflects symptom of dysphagia. Dysphagia 2006, 21, 61-65. [CrossRef]

26. Furuya, J.; Nakamura, S.; Ono, T.; Suzuki, T. Tongue pressure production while swallowing water and pudding and during dry swallow using a sensor sheet system. J. Oral Rehabil. 2012, 39, 684-691. [CrossRef]

27. Kieser, J.A.; Farland, M.G.; Jack, H.; Farella, M.; Wang, Y.; Rohrle, O. The role of oral soft tissues in swallowing function: What can tongue pressure tell us? Aust. Dent. J. 2014, 59 (Suppl. 1), 155-161. [CrossRef]

28. Rosa, R.R.; Bueno, M.D.R.S.; Migliorucci, R.R.; Brasolotto, A.G.; Genaro, K.F.; Berretin-Felix, G. Tongue function and swallowing in individuals with temporomandibular disorders. J. Appl. Oral Sci. 2020, 28, e20190355. [CrossRef] [PubMed]

29. Takeuchi, N.; Sawada, N.; Ekuni, D.; Morita, M. Oral diadochokinesis is related to decline in swallowing function among community-dwelling Japanese elderly: A cross-sectional study. Aging Clin. Exp. Res. 2021, 33, 399-405. [CrossRef] [PubMed]

30. Suzuki, M.; Koyama, S.; Kimura, Y.; Ishiyama, D.; Otobe, Y.; Nishio, N.; Ichikawa, T.; Kunieda, Y.; Ohji, S.; Ito, D.; et al. Relationship between characteristics of skeletal muscle and oral function in community-dwelling older women. Arch. Gerontol. Geriatr. 2018, 79, 171-175. [CrossRef]

31. Takahashi, K.; Amemiya, K.; Nakatsuka, M.; Nakamura, K.; Kasai, M.; Meguro, K. Impaired Eating and Swallowing Function in Older Adults in the Community: The Kurihara Project. Int. J. Environ. Res. Public Health 2019, 16, 4040. [CrossRef]

32. Haresaku, S.; Nakashima, F.; Hara, Y.; Kuroki, M.; Aoki, H.; Kubota, K.; Naito, T. Associations of Oral Health-Related Quality of Life with age, oral status, and oral function among psychiatric inpatients in Japan: A cross-sectional study. BMC Oral Health 2020, 20, 361. [CrossRef]

33. Kim, H.D.; Choi, J.B.; Yoo, S.J.; Chang, M.Y.; Lee, S.W.; Park, J.S. Tongue-to-palate resistance training improves tongue strength and oropharyngeal swallowing function in subacute stroke survivors with dysphagia. J. Oral Rehabil. 2017, 44, 59-64. [CrossRef] [PubMed]

34. Wakabayashi, H.; Matsushima, M.; Momosaki, R.; Yoshida, S.; Mutai, R.; Yodoshi, T.; Murayama, S.; Hayashi, T.; Horiguchi, R.; Ichikawa, $\mathrm{H}$. The effects of resistance training of swallowing muscles on dysphagia in older people: A cluster, randomized, controlled trial. Nutrition 2018, 48, 111-116. [CrossRef]

35. Milazzo, M.; Panepinto, A.; Sabatini, A.M.; Danti, S. Tongue Rehabilitation Device for Dysphagic Patients. Sensors 2019, $19,4657$. [CrossRef] [PubMed]

36. Park, J.S.; Lee, S.H.; Jung, S.H.; Choi, J.B.; Jung, Y.J. Tongue strengthening exercise is effective in improving the oropharyngeal muscles associated with swallowing in community-dwelling older adults in South Korea: A randomized trial. Medicine 2019, 98, e17304. [CrossRef] [PubMed]

37. Marcott, S.; Dewan, K.; Kwan, M.; Baik, F.; Lee, Y.J.; Sirjani, D. Where Dysphagia Begins: Polypharmacy and Xerostomia. Fed. Pract. 2020, 37, 234-241.

38. Shimazaki, Y.; Saito, M.; Nonoyama, T.; Tadokoro, Y. Oral Factors Associated with Swallowing Function in Independent Elders. Oral Health Prev. Dent. 2020, 18, 683-691. [CrossRef]

39. Kosaka, T.; Ono, T.; Kida, M.; Kikui, M.; Yamamoto, M.; Yasui, S.; Nokubi, T.; Maeda, Y.; Kokubo, Y.; Watanabe, M.; et al. A multifactorial model of masticatory performance: The Suita study. J. Oral Rehabil. 2016, 43, 340-347. [CrossRef]

40. Tanaka, Y.; Shiga, H. Masticatory performance of the elderly as seen from differences in occlusal support of residual teeth J. Prosthodont. Res. 2018, 62, 375-378. [CrossRef]

41. Kosaka, T.; Kida, M.; Kikui, M.; Hashimoto, S.; Fujii, K.; Yamamoto, M.; Nokubi, T.; Maeda, Y.; Hasegawa, Y.; Kokubo, Y.; et al. Factors Influencing the Changes in Masticatory Performance: The Suita Study. JDR Clin. Trans. Res. 2018, 3, 405-412. [CrossRef] [PubMed]

42. Morita, K.; Tsuka, H.; Kato, K.; Mori, T.; Nishimura, R.; Yoshida, M.; Tsuga, K. Factors related to masticatory performance in healthy elderly individuals. J. Prosthodont. Res. 2018, 62, 432-435. [CrossRef] [PubMed]

43. Sagawa, K.; Furuya, H.; Ohara, Y.; Yoshida, M.; Hirano, H.; Iijima, K.; Kikutani, T. Tongue function is important for masticatory performance in the healthy elderly: A cross-sectional survey of community-dwelling elderly. J. Prosthodont. Res. 2019, 63, 31-34. [CrossRef] [PubMed] 
44. Hara, K.; Tohara, H.; Kenichiro, K.; Yamaguchi, K.; Ariya, C.; Yoshimi, K.; Nakane, A.; Minakuchi, S. Association between tongue muscle strength and masticatory muscle strength. J. Oral Rehabil. 2019, 46, 134-139. [CrossRef]

45. Nishida, T.; Yamabe, K.; Honda, S. The Influence of Dysphagia on Nutritional and Frailty Status among Community-Dwelling Older Adults. Nutrients 2021, 13, 512. [CrossRef] 